\title{
A Positron Emission Tomographic Study of Auditory Localization in the Congenitally Blind
}

\author{
Robert Weeks, ${ }^{1}$ Barry Horwitz, ${ }^{3}$ Ali Aziz-Sultan, ${ }^{1}$ Biao Tian, ${ }^{4}$ C. Mark Wessinger, ${ }^{4}$ Leonardo G. Cohen, ${ }^{2}$ \\ Mark Hallett, ${ }^{1}$ and Josef P. Rauschecker ${ }^{4}$
}

${ }^{1}$ Human Motor Control Section, and 2 Human Cortical Physiology Section, Medical Neurology Branch, National Institute of Neurological Diseases and Stroke, and ' ${ }^{L}$ anguage Section, Voice, Speech, and Language Branch, National Institute on Deafness and Other Communication Disorders, National Institutes of Health, Bethesda, Maryland 20892, and ${ }^{4}$ Georgetown Institute for Cognitive and Computational Sciences, Georgetown University Medical Center, Washington, DC 20007

We have used positron emission tomography (PET) to measure regional cerebral blood flow (rCBF) in sighted and congenitally blind subjects performing auditory localization tasks. During scanning, the spectral and binaural cues of localized sound were reproduced by a sound system and delivered via headphones. During tasks that required auditory localization both the sighted and blind subjects strongly activated posterior parietal areas. In addition, the blind subjects activated association areas in the right occipital cortex, the foci of which were similar to areas previously identified in visual location and motion detection experiments in sighted subjects. The blind subjects, therefore, demonstrated visual to auditory crossmodal plasticity with auditory localization activating occipital association areas originally intended for dorsal-stream visual processing.

To determine the functional connectivity of pre-selected brain regions in primary and non-primary auditory and posterior pa-

The effects of visual loss on the remaining senses is a question of great interest to neuroscientists (Rauschecker, 1995; Sadato et al., 1996; Cohen et al., 1999; Kujala et al., 2000). Animal studies have shown an expansion of nonvisual at the expense of formerly visual regions after binocular deprivation (Rauschecker and Korte, 1993). In terms of behavioral abilities, improved auditory spatial abilities of blind subjects have recently been demonstrated in both animals (Rauschecker and Kniepert, 1994; King and Parsons, 1999) and humans (Muchnik et al., 1991; Lessard et al., 1998; de Volder et al., 1999; Röder et al., 1999). Human neuroimaging studies have shown that in subjects blind early in life, but not in sighted subjects, the occipital cortex is activated during Braille reading or other tactile discrimination tasks (Sadato et al., 1996; Büchel et al., 1998). No studies have been performed so far to examine the hypothesis that occipital (or other normally visual) areas participate in the processing of auditory spatial infor-

Received Oct. 18, 1999; revised Jan. 20, 2000; accepted Jan. 21, 2000.

This work was supported by National Institutes of Health Grant R01-DC03489 (J.P.R.), Department of Defense Grant DAMD17-93-V-3018 (J.P.R.), and the National Institute of Neurological Diseases and Stroke Intramural Research Program.

Correspondence should be addressed to Josef P. Rauschecker, Institute for Cognitive and Computational Sciences, Georgetown University Medical Center, WP15 NRB, 3970 Reservoir Road, NW, Washington, DC 20007. E-mail: rauscheckerj@giccs.georgetown.edu.

Copyright (C) 2000 Society for Neuroscience $0270-6474 / 00 / 202664-09 \$ 15.00 / 0$ rietal cortex in the two cohorts, we performed an inter-regional correlation analysis on the rCBF data set. During auditory localization in the blind subjects, rCBF activity in the right posterior parietal cortex was positively correlated with that in the right occipital region, whereas in sighted subjects correlations were generally negative. There were no significant positive occipital correlations in either cohort when reference regions in temporal or left parietal cortex were chosen. This indicates that in congenitally blind subjects the right occipital cortex participates in a functional network for auditory localization and that occipital activity is more likely to arise from connections with posterior parietal cortex.

Key words: blindness; cross-modal plasticity; extrastriate; parietal cortex; positron emission tomography; sound localization mation. We have, therefore, designed an experiment to determine the functional neuroanatomy of auditory localization in congenitally blind subjects and sighted control subjects. In addition to conventional subtraction analysis, we also used an interregional correlation analysis (Horwitz, 1994) of the regional cerebral blood flow (rCBF) data to determine whether the principal nodes of activation during auditory localization were functionally connected to other brain regions in similar or different ways in blind compared to sighted subjects. The choice of reference regions (bilateral primary and non-primary auditory cortices and bilateral inferior parietal lobules) was made, a priori, after analysis of the data in the sighted controls (Bushara et al., 1999; Weeks et al., 1999). The two analytical techniques (subtraction and correlation) are complementary and, when performed on the same data set, can provide a fuller understanding of the underlying neural changes during the task under study.

\section{MATERIALS AND METHODS}

Subjects. Nine congenitally blind subjects were studied (four male and five female; mean age, 42.0 years), and their results compared to those of nine, sighted control subjects (three male and six female; mean age, 38.2 years). In each group, eight of the subjects were right-handed, and one subject ambidextrous. Seven of the blind subjects were blind secondary to retinopathy of prematurity, one had bilateral anophthalmia, and another had congenital glaucoma and bilateral cataracts. None of the blind subjects had ever had object vision and none had perception of light at time of scanning. All subjects had normal neurological examinations, 
apart from their visual deficits, and normal high-resolution brain MRI scans. None of the subjects had any detectable auditory deficits or any history of auditory disease.

Auditory localization. The practicalities of PET scanning prevented auditory localization from being performed in a free-field situation. We, therefore, used sounds synthesized according to the technique described by Wightman and Kistler (1989), which is based on the assumption that if the acoustical waveforms arriving at both eardrums are the same under headphone and free-field listening conditions, then the listener's acoustical experience should also be the same (Wightman and Kistler, 1989). The technique requires simultaneous recording (from both ears) of sounds arriving from loudspeakers at several spatial positions in a freesound-field using miniature probe microphones inserted into the ear canals $1-2 \mathrm{~mm}$ from the tympanic membrane. Intensity and phase transformations of sounds recorded in the absence of the subject to those recorded from each eardrum [the free-field-to-eardrum transfer function or head-related transfer function (HRTF)] are incorporated into digital filters and used for sound synthesis (Wightman and Kistler, 1989). We used nonindividualized HRTFs (University of Wisconsin-Madison; Wenzel et al., 1993), implemented in a Tucker-Davies Technologies (Gainesville, FL) sound system to generate bandpassed bursts with a bandwidth of six octaves and a center frequency of $2 \mathrm{kHz}$. These were calibrated independently for each ear using a Brüel \& Kjaer $1 / 2$ inch condenser microphone and sound level meter and presented binaurally via well-fitting high-quality headphones (model HD 545; Sennheiser, Oldlime, CT) at $25 \mathrm{~dB}$ above each subject's left and right ear's sensation level threshold (average of three trials). The mean threshold for all subjects was $10 \mathrm{~dB}$ SPL. Sounds were perceived as coming from seven different directions $\left(-90,-60,-30,0,+30,+60\right.$, and $+90^{\circ}$, where $0^{\circ}$ is straight-ahead) within the azimuth in the frontal interaural plane (at zero elevation). Stimulus duration was $500 \mathrm{msec}$, and interstimulus interval was $2 \mathrm{sec}$ (i.e., $\sim 40$ trials per task). Presentation of stimulus location was pseudorandomized balancing right and left hemispaces in each task.

Experimental design. The paradigm consisted of four conditions. Condition one was an unconstrained rest condition (R) without sound delivered. Headphones were worn throughout and helped to reduce exposure to the ambient noise in the scanner room. Condition two consisted of passive listening (PL) to intermittent sound with the same characteristics as under active localization conditions three and four but without varying binaural differences. Sound was thereby always perceived as if coming from straight ahead or in some cases coming from "inside their head." Subjects were requested to simply listen to the sound and told that its location was of no significance. Conditions three and four consisted of the randomized delivery of localized sound from one of seven azimuth locations $\left(+90,+60,+30,0,-30,-60\right.$, and $\left.-90^{\circ}\right)$, perceived in front of the subjects. Condition three [auditory localization (AL)] was a modified delayed matching task whereby subjects successively had to make a same/different discrimination of each sound direction with that of the preceding sound. In condition four [auditory localization with movement (AM)] subjects were asked to immediately move the joystick with the right hand to indicate the stimulus direction.

Behavioral data of the accuracy of auditory localization were determined before and during scanning by a comparison of the direction of sound produced by the sound system with the direction to which the subject moved the joystick. Before scanning each subject underwent 10 trials, each consisting of 72 consecutively presented sounds to determine a prescanning mean angular error for each subject. Similar data were collected for each subject during condition four of the PET experiment. Subjects were requested not to make eye movements to the perceived sound location. Initially during training, subjects made saccadic eye movements to the perceived direction of the sound, but after a short time subjects stopped making such eye movements. To further document eye movements during auditory localization, horizontal electro-oculograms (EOGs) were recorded for three subjects after their PET scans (outside of the scanner). Saccadic eye movements were not detected in EOG recordings during the localization tasks in any of these subjects.

Scanning details and data acquisition. Each subject underwent eight sequential rCBF PET scans, two scans for each condition, in a randomized order, using the tracer $\mathrm{H}_{2}{ }^{15} \mathrm{O}$. Scans were obtained using a Scanditronix PC 2048-15b PET camera with data acquired in twodimensional (2-D) mode. The axial field of view of the scanner is $9.75 \mathrm{~cm}$ with an in-plane resolution at the center of the field of view of $6.1 \mathrm{~mm}$. For each scan, a bolus intravenous injection of $37.5 \mathrm{mCi}$ of $\mathrm{H}_{2}{ }^{15} \mathrm{O}$ in $6-8$ $\mathrm{cc}$ of normal saline was administered. After an $\sim 20 \mathrm{sec}$ delay, emission data were acquired in a $60 \mathrm{sec}$ time frame, with an interval of $10 \mathrm{~min}$ between each successive $\mathrm{H}_{2}{ }^{15} \mathrm{O}$ administration. Subjects were positioned within the scanner so that the lowermost detectors covered the most inferior temporal regions. A $10 \mathrm{~min}$ transmission scan using rotating rods of ${ }^{68} \mathrm{Ge} /{ }^{68} \mathrm{Ga}$ was performed for attenuation correction before the rCBF scans and used to reconstruct a 2-D attenuation map. The attenuationcorrected emission data were reconstructed as 15 contiguous axial planes of slice thickness $6.5 \mathrm{~mm}$. The reconstructed image planes contained $128 \times 128$ pixels, each measuring $2.09 \times 2.09 \mathrm{~mm}$.

Data analysis. All calculations and image manipulations were performed on Sun SPARC computers using Analyze version 7.1 image display software (BRU; Mayo Foundation) and Matlab (MathWorks, Natick, MA). Data analysis was performed using statistical parametric mapping (SPM95; Functional Imaging Laboratory, Queen Square, London, UK) (Friston, 1995) and "in-house" correlation programs written in Matlab.

To correct for any head movement between scans, all head images were aligned on a voxel-by-voxel basis using a three-dimensional automated image registration algorithm (Woods et al., 1992). The intercommissural (AC-PC) line was identified, and the volume was transformed into standard stereotactic space (Talairach and Tournoux, 1988). Each image was smoothed with an isotropic Gaussian filter of $12 \mathrm{~mm}$ to increase the signal-to-noise ratio. Further data processing was performed separately for the subtraction and correlation analyses and is described below.

Subtraction analysis. The SPM analysis is an implementation of the General Linear Model of statistics (Winer, 1971; Friston, 1995), equivalent to an ANOVA applied on a voxel-by-voxel basis, in which global activity and subject variability are confounding effects, and the task effect is the parameter of interest. The model was applied on a single-subject basis, and the images were scaled to a global mean rCBF of $50 \mathrm{ml}$ per 100 $\mathrm{mg} / \mathrm{min}$. The resulting set of voxel values for each contrast constitute a statistical parametric map of the $t$ statistic $\operatorname{SPM}\{t\}$. The SPM $\{t\}$ values were transformed to the unit normal distribution (SPM $\{Z\})$ and thresholded at $Z>3.09$ (equivalent to an uncorrected $p$ value $>0.001$ ). The resulting foci were then characterized in terms of peak height with a Bonferroni-like correction for the number of independent voxels giving a final $Z$ score for peak height significance of $>4$.2. We performed three groups of contrasts: group 1 consisted of three within-group comparisons in the blind subjects: (1) passive listening versus rest (PL-R), (2) delayed matching auditory localization versus rest (AL-R), and (3) auditory localization with joystick movements versus rest (AM-R). Groups 2 and 3 comprised between-group comparisons of the same three contrasts (PL-R, AL-R, and AM-R), revealing areas of relatively increased $\mathrm{rCBF}$ in the blind subjects and regions of relatively increased $\mathrm{rCBF}$ in the sighted subjects.

Correlation analysis. We used an analytical technique that assesses the within-task, across-subject, inter-regional correlations with a specified reference region (Horwitz, 1994). We chose six, a priori, reference regions from the within-group analysis of the control group data: that of a left and right primary auditory region [Brodmann areas (BA) 41/42], nonprimary auditory "association" cortex within the superior temporal gyri (BA 22), and the inferior parietal lobules (BA 40; Bushara et al., 1999; Weeks et al., 1999).

Standardized $\mathrm{rCBF}$ for each subject and each scan was evaluated as the ratio of $\mathrm{rCBF}$ in each voxel to global CBF. For each subject, the relationship between standardized $\mathrm{rCBF}$ in a reference voxel and standardized rCBF in all other brain voxels was calculated. The strength of the inter-regional relationship was assessed by an across-subject correlation, a high correlation coefficient indicating that a region is likely to be functionally connected with the reference region. The inherent assumption in this technique is that a homogenous group of subjects use a similar regional network for a task, but that each subject performs the task with a different level of rCBF change whether that be a hemodynamic effect or related to attention or task difficulty. The resulting subject-to-subject variation results in strong covariances in activity between the nodes of the network. Thresholds of significance for the within-group correlations were set at $p<0.01$ and displayed as statistical maps in standard stereotactic space. To allow statistical comparisons between the correlations in the sighted and blind subjects, the correlation maps were converted into a Gaussianized data set by a Fisher transformation followed by conventional univariate statistics to calculate $Z$ scores. Data from the between-group comparison of correlation maps were considered significant if $Z$ scores were $>4.0$. These data were then displayed in another statistical map showing regions of significant differ- 
Table 1. Within-group contrast of passive listening compared to rest

\begin{tabular}{|c|c|c|c|c|c|c|c|}
\hline \multicolumn{4}{|l|}{ Sighted subjects } & \multicolumn{4}{|l|}{ Blind subjects } \\
\hline $\begin{array}{l}\text { Cerebral regions and } \\
\text { Brodmann areas }\end{array}$ & $\begin{array}{l}\text { Talairach } \\
\text { coordinates }\end{array}$ & $\begin{array}{l}Z \\
\text { scores }\end{array}$ & $\begin{array}{l}\% \text { rCBF } \\
\text { change }\end{array}$ & $\begin{array}{l}\text { Cerebral regions and } \\
\text { Brodmann areas }\end{array}$ & $\begin{array}{l}\text { Talairach } \\
\text { coordinates }\end{array}$ & $\begin{array}{l}Z \\
\text { scores }\end{array}$ & $\begin{array}{l}\% \text { rCBF } \\
\text { change }\end{array}$ \\
\hline $\begin{array}{l}\mathrm{R} \text { auditory association cortex, } \\
\text { BA } 22\end{array}$ & $42,-40,4$ & 4.33 & 4.86 & $\begin{array}{l}\text { L primary auditory region, } \\
\text { BA } 41 / 42\end{array}$ & $-42,-28,8$ & $3.42^{*}$ & 4.05 \\
\hline $\begin{array}{l}\mathrm{L} \text { auditory association cortex, } \\
\text { BA } 22\end{array}$ & $-48,-38,8$ & 4.29 & 5.32 & $\begin{array}{l}\text { R primary auditory region, } \\
\text { BA } 41 / 42\end{array}$ & $56,-26,12$ & $2.96^{*}$ & 2.94 \\
\hline $\begin{array}{l}\text { R primary auditory region, } \\
\text { BA } 41 / 42\end{array}$ & $40,-20,8$ & $3.44^{*}$ & 3.35 & $\begin{array}{l}\text { R rostral superior temporal gyrus, } \\
\text { BA } 38\end{array}$ & $46, \quad 10,-8$ & $3.56^{*}$ & 4.02 \\
\hline \multirow[t]{2}{*}{$\begin{array}{l}\text { L primary auditory region, } \\
\text { BA } 41 / 42\end{array}$} & $-48,-26,8$ & $2.64^{*}$ & 2.38 & $\begin{array}{l}\text { R mid-frontal gyrus, } \\
\text { BA } 46\end{array}$ & $10, \quad 50,12$ & 4.28 & 5.87 \\
\hline & & & & $\begin{array}{l}\mathrm{R} \text { auditory association } \\
\text { cortex, BA } 22\end{array}$ & $44,-36,12$ & $3.11^{*}$ & 3.41 \\
\hline
\end{tabular}

*Peak areas of activation in superior temporal gyrus are listed despite lack of significance at $Z$ 4.20.

Table 2. Within-group contrast of delayed matching auditory localization task compared to rest

Sighted subjects

Cerebral regions and
Brodmann areas

Brodmann areas

$\mathrm{R}$ inferior parietal lobule, BA 40

$\mathrm{L}$ inferior parietal lobule, BA 40

L auditory association, BA 22

R medial frontal gyrus, BA 11

$\mathrm{R}$ middle frontal gyrus, BA 9/46

$\mathrm{R}$ inferior temporal gyrus, BA 20

\begin{tabular}{|c|c|c|}
\hline $\begin{array}{l}\text { Talairach } \\
\text { coordinates }\end{array}$ & $\begin{array}{l}Z \\
\text { scores }\end{array}$ & $\begin{array}{l}\% \mathrm{rCBF} \\
\text { change }\end{array}$ \\
\hline $42,-48, \quad 32$ & 5.92 & 7.00 \\
\hline$-42,-48, \quad 36$ & 5.55 & 5.77 \\
\hline$-52,-40, \quad 8$ & 4.25 & 4.36 \\
\hline $16, \quad 38,-12$ & 5.29 & 8.06 \\
\hline $34, \quad 34, \quad 24$ & 4.93 & 5.93 \\
\hline $50,-38,-12$ & 4.96 & 5.60 \\
\hline
\end{tabular}

$\mathrm{R}$

Blind subjects

\begin{tabular}{lrll}
\hline $\begin{array}{l}\text { Cerebral regions and } \\
\text { Brodmann areas }\end{array}$ & $\begin{array}{l}\text { Talairach } \\
\text { coordinates }\end{array}$ & $\begin{array}{l}Z \\
\text { scores }\end{array}$ & $\begin{array}{l}\text { \% rCBF } \\
\text { change }\end{array}$ \\
\hline R inferior parietal lobule, BA 40 & $32,-56,36$ & 7.17 & 8.55 \\
R parieto-occipital cortex, BA 19 & $22,-70,40$ & 5.67 & 7.83 \\
R dorsal occipital cortex, BA 18 & $24,-82,8$ & 4.88 & 6.60 \\
L parieto-occipital cortex, BA 19 & $-18,-72,40$ & 4.22 & 4.82 \\
R dorsal premotor, BA 6 & $36, \quad 0,40$ & 6.21 & 6.34 \\
R ventral premotor, BA 6 & $44, \quad 6,24$ & 5.09 & 5.37 \\
R inferior lateral prefrontal & $36, \quad 46,8$ & 5.08 & 5.91
\end{tabular}

cortex, BA 46 ence between the correlation maps of the sighted and blind subjects. Subjects performed each condition twice and within-task correlations were corrected for the nonindependence of the two data sets from each subject (Horwitz et al., 1998).

\section{RESULTS}

The behavioral data collected before scanning showed a mean angular error during auditory localization with joystick movements of $23.8^{\circ}(\mathrm{SD}, 4.4)$ in the sighted subjects and $22.2^{\circ}(\mathrm{SD}, 4.3)$ in the blind subjects. During scanning the mean error was $21.1^{\circ}$ (SD, 1.9) in the sighted subjects and $21.6^{\circ}(\mathrm{SD}, 4.5)$ in the blind subjects. There were no significant differences between the blind and sighted cohorts in terms of angular error.

\section{Subtraction analysis}

Tables 1-3 list the within-group comparisons in the sighted and blind cohorts. The data from the sighted subjects have been documented fully in a previous paper (Weeks et al., 1999) and will only be discussed in relation to the data from the blind subjects.

Table 1 lists the areas of activation in the passive listening versus rest comparison in sighted and blind subjects. In general, levels of activation were not high in this comparison in either of the studied cohorts. Because of interest in superior temporal gyral activation, we have listed all peaks of activation in this area irrespective of significance levels.

In Table 2 are listed the results of the within-group comparison of the auditory localization and delayed matching task compared to rest in the two cohorts. The blind subjects activated a number of areas in this task, including right inferior parietal lobule (IPL; BA 40), bilateral parieto-occipital cortex (BA 19), right dorsal occipital cortex (BA 18), right dorsal and ventral premotor areas (BA 6), and a right prefrontal area (BA 46). The areas of activation in the blind subjects for the within-group comparison AL-R are illustrated in Figure $1 A$. The sighted subjects activated bilateral IPL (BA 40), left auditory association cortex (BA 22), right inferior temporal cortex (BA 20), and areas in the right prefrontal cortex (BA 11 and 9/46). The sighted subjects did not activate parieto-occipital cortex or dorsal occipital visual association areas.

Table 3 documents the results of the within-group comparison of auditory localization with joystick movement against rest. The blind subjects activated bilateral IPL (BA 40), bilateral parietooccipital areas (BA 19), contralateral (to the moving hand) sensorimotor cortex (BA 1, 2, 3, and 4) and anterior cingulate cortex (BA 24), and bilateral cerebellar hemispheres and ipsilateral ventral premotor areas (BA 6). The sighted subjects activated bilateral IPL (BA 40) and movement-related areas in similar locations to the blind cohort but did not activate parieto-occipital cortices. The areas of activation in the blind subjects for the within-group comparison AM-R are illustrated in Figure $1 B$.

Table 4 lists the results of the between-group contrasts showing regions of relatively increased activation in the blind and in the sighted cohort. There were no significant between-group differences, either increases in blind or sighted subjects, in the PL-R comparison. The regions of increased activation in the blind in 
A
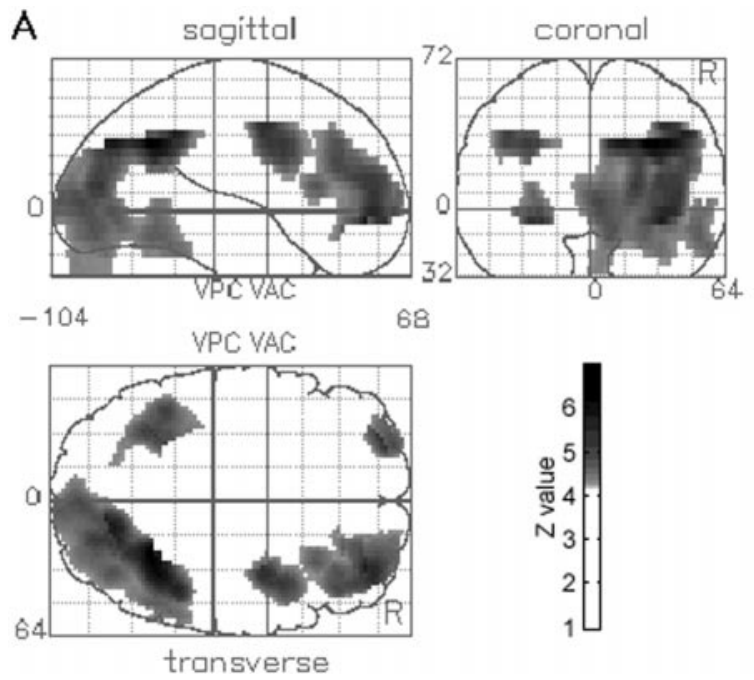

B
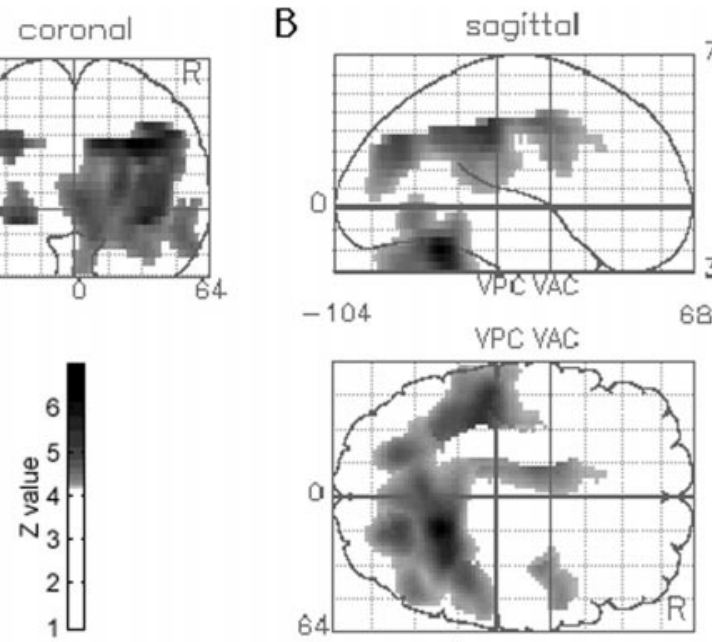

$-104$

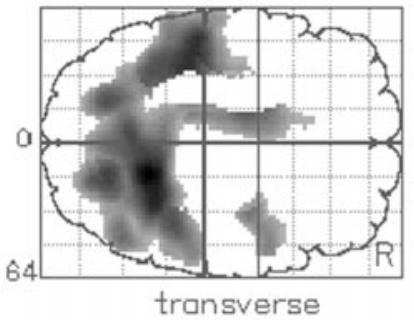

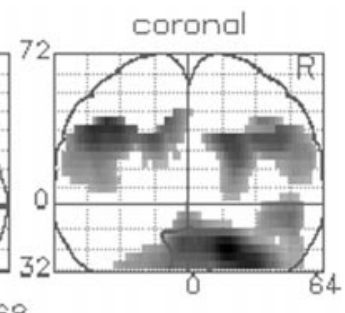

68

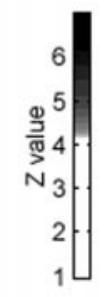

Figure 1. Statistical parametric maps of increased regional cerebral blood flow in the blind subjects compared to rest. All areas shown are significant at $Z>4.2$ after Bonferroni correction for multiple comparisons (see "Subtraction analysis" in Materials and Methods). $A$ illustrates the within-group comparison of auditory localization and delayed-matching compared to rest, and $B$ shows the comparison of auditory localization with movement versus rest.

Table 3. Within-group contrast of auditory localization and joystick movement compared to rest

Sighted subjects

\begin{tabular}{|c|c|c|c|c|}
\hline $\begin{array}{l}\text { Cerebral regions and } \\
\text { Brodmann areas }\end{array}$ & $\begin{array}{l}\text { Talairach } \\
\text { coordinates }\end{array}$ & $\begin{array}{l}Z \\
\text { scores }\end{array}$ & $\begin{array}{l}\% \mathrm{rCBF} \\
\text { change }\end{array}$ & $\begin{array}{l}\text { Cerebral regions and } \\
\text { Brodmann areas }\end{array}$ \\
\hline $\begin{array}{l}\text { L sensorimotor cortex, } \\
\text { BA } 1,2,3,4\end{array}$ & $-52,-24,36$ & 6.12 & 7.08 & $\begin{array}{l}\text { L sensorimotor cortex, } \\
\text { BA } 1,2,3,4\end{array}$ \\
\hline $\mathrm{L}$ inferior parietal cortex, BA 40 & $-40,-44,36$ & 5.16 & 6.38 & $\mathrm{~L}$ inferior parietal cortex, BA 40 \\
\hline $\mathrm{R}$ inferior parietal cortex, BA 40 & $46,-42,28$ & 4.31 & 4.34 & L parieto-occipital cortex, BA 19 \\
\hline $\mathrm{L}$ anterior cingulate, BA 24 & $-6,-2,44$ & 4.21 & 4.39 & $\mathrm{R}$ inferior parietal cortex, BA 40 \\
\hline $\mathrm{R}$ cerebellar dentate nucleus & $10,-56,-20$ & 6.74 & 10.77 & $\mathrm{R}$ parieto-occipital cortex, $\mathrm{BA} 1 \mathrm{~s}$ \\
\hline $\mathrm{L}$ lateral cerebellar hemishere & $-32,-70,-28$ & 4.26 & 4.32 & $\begin{array}{l}\text { L cerebellar dentate nucleus } \\
\text { Cerebellar vermis } \\
\text { R cerebellar hemisphere } \\
\text { R ventral premotor, BA } 6 \\
\text { L ant. cingulate, BA } 24\end{array}$ \\
\hline
\end{tabular}

Blind subjects

$\mathrm{L}$ ant. cingulate, BA 24

\begin{tabular}{lll}
$\begin{array}{l}\text { Talairach } \\
\text { coordinates }\end{array}$ & $\begin{array}{l}Z \\
\text { scores }\end{array}$ & $\begin{array}{l}\text { \% rCBF } \\
\text { change }\end{array}$ \\
$-48,-30,36$ & 5.78 & 7.59 \\
& & \\
$-36,-44,40$ & 4.98 & 6.21 \\
$-18,-72,40$ & 6.58 & 8.31 \\
$28,-58,40$ & 6.94 & 7.73 \\
$12,-72,40$ & 6.76 & 8.62 \\
$16,-52,-20$ & 7.24 & 9.92 \\
$4,-56,-16$ & 5.09 & 7.06 \\
$28,-50,-28$ & 6.55 & 8.60 \\
$46, \quad 4,20$ & 5.42 & 4.64 \\
$-12,-8,40$ & 4.27 & 6.67 \\
\hline
\end{tabular}

the AL-R task are listed in Table $4 a$ and in the AM-R task in Table $4 b$. The results of both contrasts indicate two regions of statistically increased activation in the blind subjects both in the right occipital cortex, one situated in the dorsal occipital cortex (comprising parts of BA 18 and 19) and another in the ventral occipital cortex (BA 19). The normalized rCBF values for each task show that the changes are a composite of a deactivation in the sighted subjects of $\sim 2-3 \%$ of the initial resting rCBF value and an additional 5-6\% increase in rCBF in the blind subjects, when compared to the initial resting $\mathrm{rCBF}$ level. The data from Table $4 a$, showing relatively increased activation in the blind cohort in the AL-R contrast, are illustrated in Figure $2 A$ (the results listed in Table $4 b$ are very similar and are not illustrated).

The rCBF increases in the sighted subjects compared to the blind in the AL-R task are listed in Table $4 c$ and illustrated in Figure $2 B$. The sighted subjects had relatively increased activation during the AL task in left inferior temporal areas (BA 20). The area of activation extends superiorly into posterior parietal areas with separate subpeaks in this region, but none of them reached significance. There were no areas of relatively increased activation in the sighted cohort in the AM-R contrast.

\section{Correlation analysis}

Six reference regions were chosen, as described in Materials and Methods. The results for the within-condition, inter-regional correlations for the right and left IPL reference regions in the delayed-matching auditory localization condition (AL-R) are shown in Tables 5 and 6 . The tables indicate the significant $(p<$ 0.01 ) positive and negative correlations for blind and sighted subjects and any significant differences between the inter-regional correlation maps of the two cohorts.

When the right IPL was used as the reference region in the sighted subjects, there were highly significant positive correlations with right auditory cortex (BA 41/42) and left IPL (BA 40) and negative correlations with bilateral dorsal occipital (BA 18), left peristriate cortex (BA 18), right ventral occipital cortex (BA 18), and two regions in the right inferior temporal cortex (BA 20/37). The same reference region in the blind subjects revealed positive 
Table 4. Between-group contrast showing areas with increased activation in the blind and sighted cohorts

Normalized rCBF values

Sighted Blind

\begin{tabular}{|c|c|c|c|c|c|c|}
\hline \multirow[b]{2}{*}{$\begin{array}{l}\text { Cerebral regions and } \\
\text { Brodmann areas }\end{array}$} & \multirow[b]{2}{*}{$\begin{array}{l}\text { Talairach } \\
\text { coordinates }\end{array}$} & \multicolumn{2}{|c|}{ Sighted } & \multicolumn{2}{|l|}{ Blind } & \multirow[b]{2}{*}{$\begin{array}{l}Z \\
\text { scores }\end{array}$} \\
\hline & & Rest & $\mathrm{AL}$ or $\mathrm{AM}$ & Rest & $\mathrm{AL}$ or $\mathrm{AM}$ & \\
\hline $\mathrm{R}$ dorsal occipital cortex, BA 18 & $20,-84,12$ & 65.53 & 63.87 & 69.69 & 73.68 & 4.34 \\
\hline $\mathrm{R}$ ventral occipital cortex, BA 18 & $34,-76,0$ & 63.75 & 61.59 & 67.58 & 71.17 & 4.30 \\
\hline
\end{tabular}

b. Relatively increased activation in the blind in the localization with joystick movements versus rest contrast

$\begin{array}{lllllll}\text { R dorsal occipital cortex, BA } 19 & 22,-76,24 & 73.97 & 73.23 & 73.54 & 77.99 & 4.59 \\ \text { R ventral occipital cortex, BA } 18 & 40,-68,-4 & 70.05 & 67.83 & 74.81 & 78.71\end{array}$

c. Relatively increased activation in the sighted in the delayed matching versus rest contrast

\begin{tabular}{llllll} 
L inf. temporal cortex, BA 21 & $-60,-28,-12$ & 59.99 & 62.86 & 61.59 & 59.92 \\
\hline
\end{tabular}

A
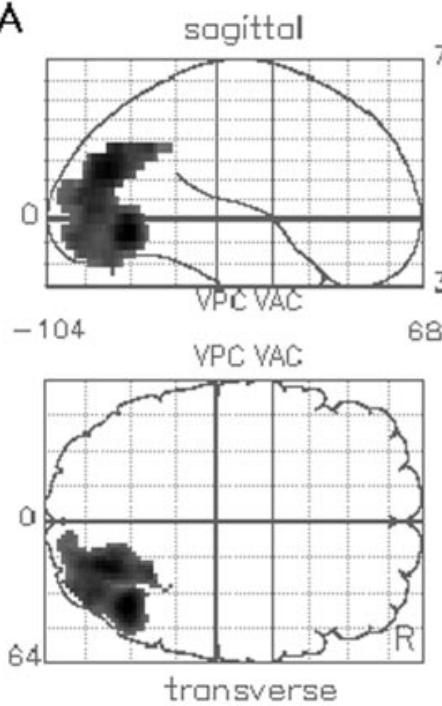

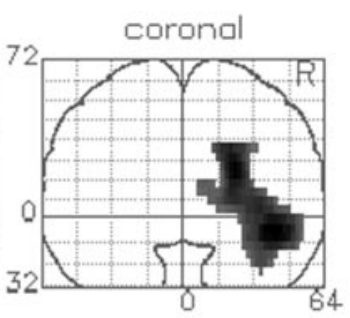

68
B
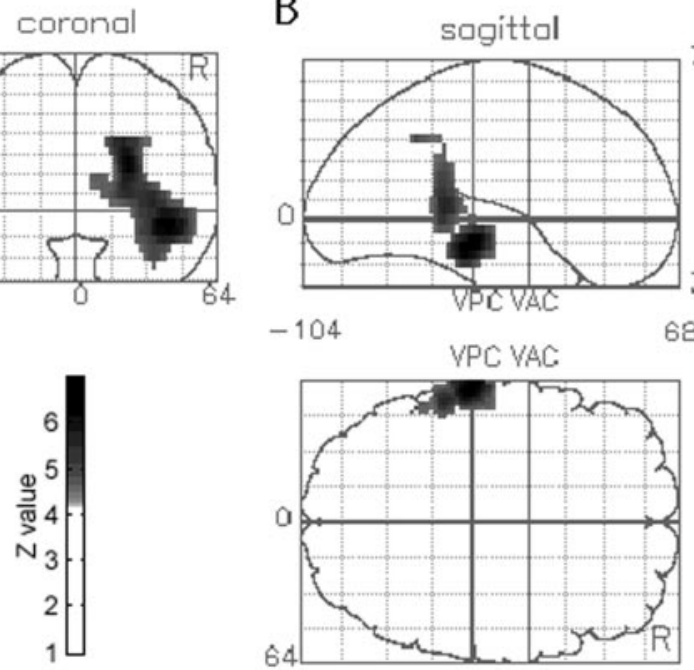

$-104$

VPC VAC

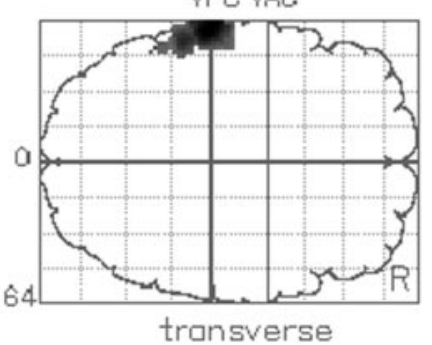

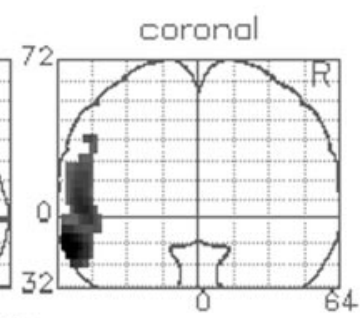

68

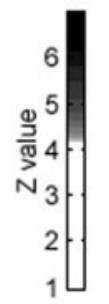

Figure 2. Statistical parametric maps from the between-group contrasts showing regions of relatively increased activation in the blind and regions of enhanced activation in the sighted cohort. $A$ shows relatively increased activation in the blind cohort compared to the sighted in the auditory localization and delayed matching compared to rest contrast. The rCBF increases in the sighted subjects compared to the blind in the same task are shown in $B$.

correlations with right superior temporal gyrus (BA 42), right inferior and middle temporal cortex (BA 20 and 21), left IPL (BA 40), right parieto-occipital (BA 7/19), right dorsal occipital (BA 19), right peristriate cortex (BA 18) and two areas in ventral occipital cortex (BA 19) without any significant negative interregional correlations. The comparison between the two sets of correlations revealed that in the blind subjects there were significantly greater inter-regional correlations than the sighted subjects between the right IPL and the right parieto-occipital (BA 7/19), right ventral and dorsal occipital (BA 19), right peristriate (BA 18), and right superior and inferior temporal cortices (BA 20 and 22). There were no significantly increased inter-regional correlations in the sighted cohort compared to the blind subjects.

The inter-regional correlations for the right IPL region are illustrated as statistical maps in standard stereotactic space in Figure $3 A-C$.
When the left IPL was used as the reference region, the sighted subjects had positive correlations with left superior temporal gyrus (STG) (BA 22), right STG (BA 41/42), and right IPL (BA 40). There were negative correlations with bilateral parietooccipital (BA 7/19), left ventral occipital areas (BA 19), and middle temporal gyrus (BA 21). In the blind subjects, left IPL was positively correlated with right IPL (BA 40) and two areas in the right STG (BA 41/42 and 22) and negatively correlated with left parieto-occipital (BA 7/19), left peristriate (BA 18), and left dorsal occipital cortex (BA 18). When the two sets of interregional correlations were compared, in the blind subjects, there were greater positive correlations between the left IPL and two regions in the right STG (BA 42 and 22) and a region in the right fusiform gyrus (BA 19). There were no areas with significantly increased inter-regional correlations in the sighted cohort compared to the blind subjects for the left IPL reference region. The 


\begin{tabular}{|c|c|c|c|c|c|c|c|c|}
\hline \multicolumn{3}{|l|}{ Sighted subjects } & \multicolumn{3}{|l|}{ Blind subjects } & \multicolumn{3}{|l|}{ Statistical comparison } \\
\hline $\begin{array}{l}\text { Cerebral regions and } \\
\text { Brodmann areas }\end{array}$ & $\begin{array}{l}\text { Talairach } \\
\text { coordinates }\end{array}$ & $\begin{array}{l}r \\
\text { value }\end{array}$ & $\begin{array}{l}\text { Cerebral regions and } \\
\text { Brodmann areas }\end{array}$ & $\begin{array}{l}\text { Talairach } \\
\text { coordinates }\end{array}$ & $\begin{array}{l}r \\
\text { value }\end{array}$ & $\begin{array}{l}\text { Cerebral regions and } \\
\text { Brodmann areas }\end{array}$ & $\begin{array}{l}\text { Talairach } \\
\text { coordinates }\end{array}$ & $\begin{array}{l}Z \\
\text { score }\end{array}$ \\
\hline $\begin{array}{l}\text { R primary auditory } \\
\text { cortex, BA } 41 / 42\end{array}$ & $62,-28,8$ & 0.86 & $\begin{array}{l}\text { R Superior temporal } \\
\text { gyrus, BA } 42\end{array}$ & $40,-10,0$ & 0.76 & $\begin{array}{l}\text { R Superior temporal } \\
\text { gyrus, BA } 22\end{array}$ & $38,-38,16$ & 4.97 \\
\hline $\begin{array}{l}\mathrm{L} \text { inferior parietal } \\
\text { lobule, BA } 40\end{array}$ & $-44,-42,36$ & 0.86 & $\begin{array}{l}\mathrm{L} \text { inferior parietal } \\
\text { lobule, BA } 40\end{array}$ & $-40,-54,32$ & 0.75 & $\begin{array}{l}\text { R fusiform gyrus, } \\
\text { BA } 37\end{array}$ & $26,-50,-12$ & 4.92 \\
\hline $\begin{array}{l}\mathrm{R} \text { inferior temporal, } \\
\text { BA } 20 / 37\end{array}$ & $36,-38,-16$ & -0.81 & $\begin{array}{l}\mathrm{R} \text { middle temporal } \\
\text { gyrus, BA } 21\end{array}$ & $48,-48,-4$ & 0.83 & $\begin{array}{l}\mathrm{R} \text { inferior temporal, } \\
\text { BA } 20\end{array}$ & $40,-28,-16$ & 4.85 \\
\hline $\begin{array}{l}\mathrm{R} \text { inferior temporal, } \\
\text { BA } 37\end{array}$ & $34,-52,-8$ & -0.85 & $\begin{array}{l}\mathrm{R} \text { inferior temporal } \\
\text { gyrus, BA } 20 / 21\end{array}$ & $40,-26,-16$ & 0.78 & $\begin{array}{l}\text { R dorsal occipital } \\
\text { cortex, BA } 19\end{array}$ & $46,-70,12$ & 4.09 \\
\hline $\begin{array}{l}\text { L peristriate cortex, } \\
\text { BA } 18\end{array}$ & $-12,-68,4$ & -0.87 & $\begin{array}{l}\text { R dorsal occipital, } \\
\text { BA } 19\end{array}$ & $48,-70,16$ & 0.83 & $\begin{array}{l}\text { R peristriate cortex, } \\
\text { BA } 18\end{array}$ & $26,-84,0$ & 4.05 \\
\hline $\begin{array}{l}\text { L parieto-occipital, } \\
\text { BA } 7 / 19\end{array}$ & $-12,-66,28$ & -0.86 & $\begin{array}{l}\text { R ventral occipital, } \\
\text { BA } 19\end{array}$ & $50,-74,-12$ & 0.75 & $\begin{array}{l}\text { R ventral occipital } \\
\text { cortex, BA } 19\end{array}$ & $50,-70,-16$ & 5.51 \\
\hline $\begin{array}{l}\text { R parieto-occipital, } \\
\text { BA } 7 / 19\end{array}$ & $6,-66,24$ & -0.73 & $\begin{array}{l}\text { R parieto-occipital, } \\
\text { BA } 7 / 19\end{array}$ & $12,-60,24$ & 0.73 & $\begin{array}{l}\text { R parieto-occipital, } \\
\text { BA } 7 / 19\end{array}$ & $16,-60,28$ & 4.21 \\
\hline \multirow[t]{2}{*}{$\begin{array}{l}\text { R ventral occipital, } \\
\text { BA } 18\end{array}$} & $30,-84,0$ & -0.75 & $\begin{array}{l}\text { R peristriate cortex, } \\
\text { BA } 18\end{array}$ & $18,-80,0$ & 0.68 & & & \\
\hline & & & $\mathrm{R}$ ventral occ., BA 19 & $10,-66,-4$ & 0.64 & & & \\
\hline
\end{tabular}

\begin{tabular}{|c|c|c|c|c|c|c|c|c|}
\hline \multicolumn{3}{|l|}{ Sighted subjects } & \multicolumn{3}{|l|}{ Blind subjects } & \multicolumn{3}{|l|}{ Statistical comparison } \\
\hline $\begin{array}{l}\text { Cerebral regions } \\
\text { and Brodmann area }\end{array}$ & $\begin{array}{l}\text { Talairach } \\
\text { coordinates }\end{array}$ & $r$ value & $\begin{array}{l}\text { Cerebral regions } \\
\text { and Brodmann area }\end{array}$ & $\begin{array}{l}\text { Talairach } \\
\text { coordinates }\end{array}$ & $r$ value & $\begin{array}{l}\text { Cerebral regions } \\
\text { and Brodmann area }\end{array}$ & $\begin{array}{l}\text { Talairach } \\
\text { coordinates }\end{array}$ & $r$ value \\
\hline $\begin{array}{l}\text { R primary auditory } \\
\text { cortex, BA } 41 / 42\end{array}$ & $58,-28,8$ & 0.79 & $\begin{array}{l}\text { R superior temporal } \\
\text { gyrus, BA } 22\end{array}$ & $50,-28,16$ & 0.81 & $\begin{array}{l}\text { R transverse tempo- } \\
\text { ral gyrus, BA } 42\end{array}$ & $40,-22,8$ & 4.99 \\
\hline $\begin{array}{l}\mathrm{R} \text { inferior parietal } \\
\text { lobule, BA } 40\end{array}$ & $38,-36,36$ & 0.98 & $\begin{array}{c}\mathrm{R} \text { inferior parietal } \\
\text { lobule, BA } 40\end{array}$ & $30,-42,44$ & 0.92 & $\begin{array}{l}\text { R fusiform gyrus, } \\
\text { BA } 37 / 19\end{array}$ & $30,-52,-8$ & 4.28 \\
\hline $\begin{array}{l}\text { L superior temporal } \\
\text { gyrus, BA } 22\end{array}$ & $-62,-44,16$ & 0.79 & $\begin{array}{l}\mathrm{R} \text { primary auditory } \\
\text { cortex, BA } 41 / 42\end{array}$ & $50,-28,4$ & 0.75 & $\begin{array}{l}\mathrm{R} \text { superior temporal } \\
\text { gyrus, BA } 22\end{array}$ & $46,-44,12$ & 3.93 \\
\hline $\begin{array}{l}\text { L middle temporal } \\
\text { gyrus, BA } 21\end{array}$ & $-46,-42,-8$ & -0.88 & $\begin{array}{l}\text { L peristriate cortex, } \\
\text { BA } 18\end{array}$ & $-14,-88,8$ & -0.88 & & & \\
\hline $\begin{array}{l}\text { L parieto-occipital, } \\
\text { BA } 7 / 19\end{array}$ & $-12,-64,24$ & -0.89 & $\begin{array}{l}\text { L parieto-occipital, } \\
\text { BA } 7 / 19\end{array}$ & $-20,-60,28$ & -0.83 & & & \\
\hline $\begin{array}{l}\text { R parieto-occipital, } \\
\text { BA } 7 / 19\end{array}$ & $6,-64,24$ & -0.91 & $\begin{array}{l}\text { L dorsal occipital, } \\
\text { BA } 18\end{array}$ & $24,-72,16$ & -0.86 & & & \\
\hline $\begin{array}{l}\text { L ventral occipital, } \\
\text { BA } 19\end{array}$ & $-44,-72,-12$ & -0.91 & & & & & & \\
\hline
\end{tabular}

correlation maps for the auditory localization and joystick movements condition (AM-R) revealed a very similar pattern of inter-regional correlations to that discussed above for both IPL foci.

We also placed reference regions in superior temporal areas whose location were identified from the subtraction analysis in the sighted subjects. The results showed positive correlations withcontralateral STG and posterior parietal areas but not with other cortical regions. There were no significant differences between the inter-regional correlations of the sighted and blind cohorts for reference regions in STG.

After the results of the subtraction and correlation analysis revealed extensive occipital activation in the congenitally blind subjects, we placed another reference region in right occipital cortex. Using this reference region there were significant negative correlations with IPL regions in the sighted subjects and positive correlations with the right IPL in the blind subjects. However, apart from these regions there were very few other significant areas of inter-regional correlation, and the analysis did not add further information to that provided already.

\section{DISCUSSION}

The behavioral data collected during PET scanning show that the sighted and blind cohorts perform similarly, in terms of angular errors, during the auditory localization task with joystick movement (AM), and thus performance differences cannot readily 


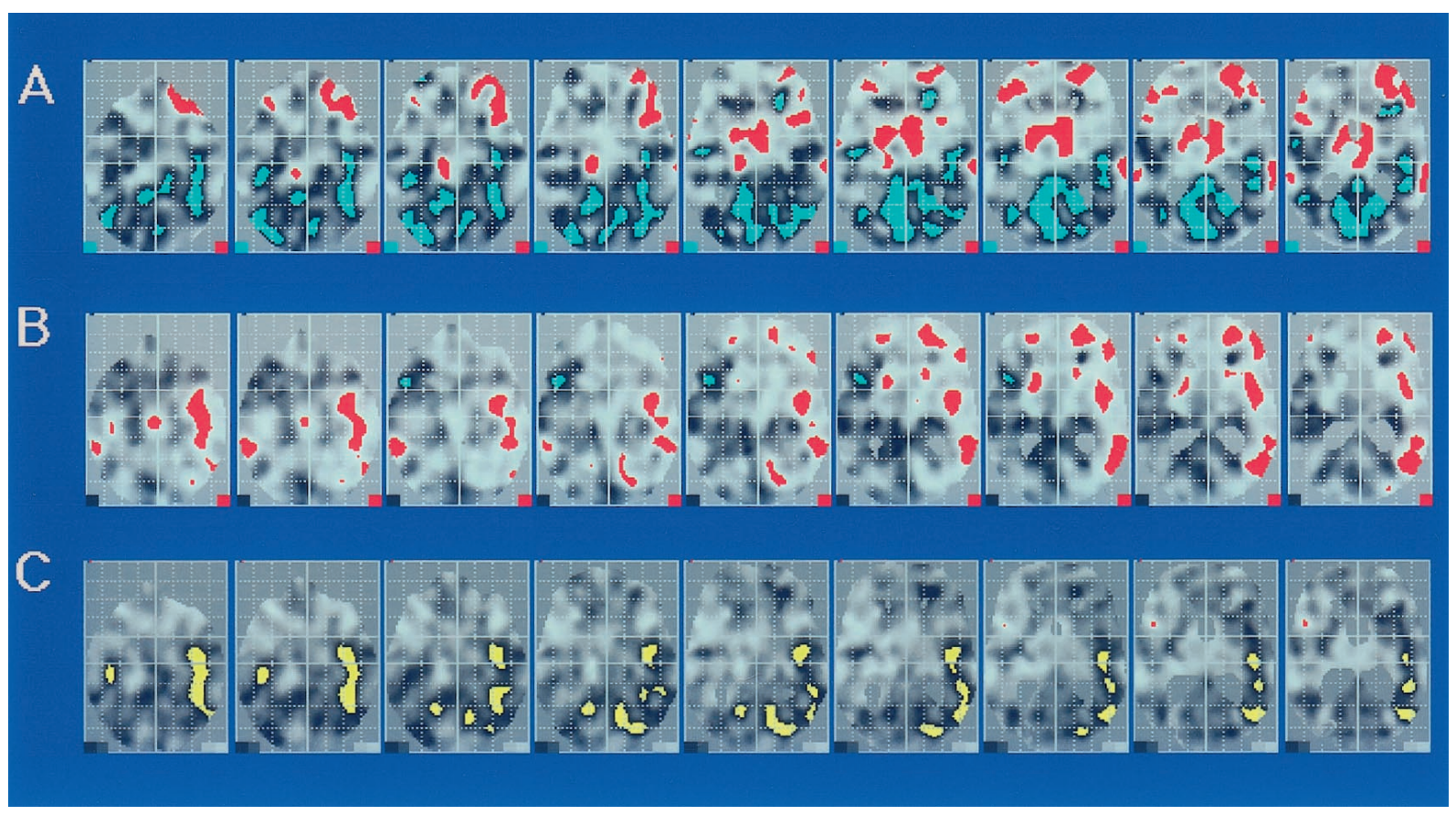

Figure 3. Inter-regional correlations for the right IPL region (Talairach coordinates, $42,-48,32$ ) in the delayed-matching auditory-localization condition for sighted $(A)$ and blind $(B)$ subjects. Correlations are displayed as statistical maps in standard stereotactic space (left side of the image corresponds to the left side of the brain). The values of the correlation coefficients are given by a gray scale, with positive correlations in white and negative correlations in black; significant positive correlations $(p<0.01)$ are shown in red, and significant negative correlations are shown in blue. Nine representative horizontal sections are shown, from left to right, at $-16,-12,-8,-4,0,4,8,12$, and 16 mm relative to the AC-PC line, covering the majority of the occipital lobe. $C$ shows regions with significantly different correlation coefficients $(p<0.05)$ between the sighted and blind cohorts. Correlations significantly larger in sighted subjects are displayed in red, and those greater in blind subjects are displayed in yellow.

explain any differences in the activation patterns of the two cohorts. Because of the use of nonindividualized HRTFs the mean errors in localization, as measured by joystick movements, are relatively large in both groups. However, the size of the localization errors is smaller than the angular distance between the (virtual) sound sources and, therefore, does not impact on the interpretation of our data. Eye movements are also unlikely to be a confounding factor, because electro-oculographic recordings clearly showed that after a period of training subjects did not make such movements. Furthermore, even if subjects had only learned to suppress their overt eye movements while still making eye movement plans, this should not influence activation in parietal cortex, because neuronal responses in this brain region are independent of the intention to perform specific motor acts (Colby and Goldberg, 1999). Congenitally blind subjects, in particular, are unlikely to perform many more eye movements that could explain the increased activation in parietal and occipital cortex found in our study.

In both sighted and blind subjects, the PL task evoked only modest bilateral activation of primary and secondary auditory areas in the STG compared to the R condition, as evident from lower levels of significance (Table 1). Similar lack of STG activation during PL has been reported in other auditory imaging studies (Griffiths and Brown, 1991; Grady et al., 1997). The reason for this is unclear but may be related to the stimulus specificity of neurons in the STG, for which broad-band noise bursts, as used here, are not the optimal stimuli (Rauschecker et al., 1995). Alternatively, the apparent lack of STG activation in the PL-R comparison could be attributable to STG activation in the unconstrained "rest" state.

Highly significant STG activation was also not a striking feature in the other contrasts (Tables 2, 3). However, during both experimental tasks that required auditory localization (AL and AM) the correlation analysis identified regions within the STG as highly correlated with the posterior parietal reference region. This suggests that during the AL and AM tasks, areas in the STG are important components of a functional network for the localization of sounds but that overall activation levels in the STG, at least when measured against a rest state, may not necessarily be high.

The between-group contrasts of AL-R and AM-R both identified two regions of increased activation in the blind subjects, one situated in dorsal right occipital cortex (Talairach coordinates 20, $-84,12$, and $22,-76,24$ for the AL-R and AM-R contrasts, respectively) and another in lateral ventral right occipital cortex (Talairach coordinates $34,-76,0$ and $40,-68,-4$ for the AL-R and AM-R contrasts, respectively). There were no significant differences in activation between the sighted and blind cohorts in the PL-R task. This indicates that the increased occipital activation of blind subjects in the AL and AM conditions is task-related and dependent on additional processing of auditory spatial information.

Correlation analysis provides further information regarding the function of the right occipital cortex during auditory localization in the blind. Activity in the right posterior parietal region was positively correlated with right occipital cortex in the blind subjects and negatively correlated in the sighted subjects. The between-group differences in the inter-regional correlations between IPL and right occipital cortex were highly significant. This confirms that in the blind a major reorganization of pathways has taken place between the right occipital area and the right IPL region (the two becoming functionally connected to each other) 
and demonstrates that the right occipital cortex in the blind has become part of the functional network for auditory localization. This constitutes important additional information, as regional activation alone, in terms of increased activity relative to a control state, does not necessarily indicate functional involvement in a task, and could theoretically represent processes not under experimental control or incidental to the experimental task (Horwitz and McIntosh, 1993).

It seems, therefore, that during auditory localization the congenitally blind subjects recruit extrastriate occipital areas normally used for visual processing, and thus they demonstrate visual-auditory cross-modal plasticity. Such recruitment of additional cortical areas for auditory localization in the blind may provide a neural basis for the corresponding behavioral improvement reported in congenitally blind humans (Muchnik et al., 1991; Lessard et al., 1998; Röder et al., 1999) and in visually deprived experimental animals (Rauschecker and Kniepert, 1994; King and Parsons, 1999). Extensive reorganization of the occipital cortex during an early period of life (Cohen et al., 1999), which cannot be reversed later, may also help to explain why congenitally blind humans and experimental animals who regain their sight later in life may not regain their vision even after years of training (von Senden, 1932; Hubel and Wiesel, 1970; Jay et al., 1987). Cross-modal cortical reorganization has also been demonstrated by neuroimaging studies in deaf subjects (Levänen et al., 1998; Neville et al., 1998).

Inspection of the activation patterns in the AL-R and AM-R within-group comparisons in the blind subjects indicate that the peaks of right IPL activation are shifted posteriorly, compared to the sighted controls ( 8 and $16 \mathrm{~mm}$ for the AL-R and AM-R comparisons, respectively), and that the blind subjects activate a large area of cortex extending posteriorly from the IPL region, including parieto-occipital and dorsal occipital regions. Conventional subtraction analysis is insensitive toward detecting shifts in peak activation and consequently, in the blind versus sighted between-group comparisons of the AL-R and AM-R contrasts, there were no significant differences in activation in the right IPL and right parieto-occipital regions. However, the correlation method clearly showed that inter-regional correlations between the right IPL and parieto-occipital regions in the blind were significantly different to those in sighted subjects, whereas correlations between reference regions in STG and occipital areas were not significant. This may tentatively be interpreted in the sense that auditory information from the STG reaches the occipital areas only indirectly via the IPL region.

The two foci of enhanced right occipital activation in the congenitally blind are in a similar location as those reported in PET studies of visual spatial (Talairach coordinates 24, -76, 24) (Haxby et al., 1994) and visual motion processing (Talairach coordinates 40, -68, 0) (Watson et al., 1993) in sighted subjects. The similarity between the foci of occipital activation during visual spatial processing in sighted subjects and auditory localization in the blind suggests that in the latter these extrastriate areas retain a similar functional role and similar principles of neuronal coding, albeit in a different modality.

Auditory areas in the posterior parietal cortex have previously been shown to be involved in the spatial processing of sounds (Griffiths et al., 1998; Bushara et al., 1999; Weeks et al., 1999) and are thought to be part of a dorsal stream in auditory processing (Rauschecker, 1998; Romanski et al., 1999), analogous to the dorsal stream in visual spatial processing (Ungerleider and Mishkin, 1982; DeYoe and Van Essen, 1988; Haxby et al., 1994). It is conceivable that during a sensitive period of early postnatal development extensive remodeling occurs in the blind via a succession of local synaptic changes beginning in posterior parietal cortex and linking IPL with parieto-occipital, dorsal occipital cortex, and other extrastriate areas. In support of cross-modal plasticity of parietal cortex, auditory responses in parietal areas of nonhuman primates seem to depend on experience and training (Stricanne et al., 1996; Grunewald et al., 1999). In cats visually deprived from birth, visual areas in the anterior ectosylvian sulcus (possibly the cat's homolog of parietal cortex in primates) are taken over by auditory input (Rauschecker and Korte, 1993). It has been suggested that such cortical plasticity is caused by cross-modal competition for synaptic space on target neurons of multimodal association cortex and is implemented via Hebbian changes of synaptic efficacy (Hebb, 1949; Rauschecker, 1995).

We have shown an exaggerated right hemispheric dominance in the congenitally blind subjects, not only for occipital but also parietal and temporal regions. An indication of this was given in the subtraction analysis when greater activation of left temporal and parietal areas was observed in sighted compared to blind subjects in the AL-R contrast (Table 4c). This was even more clearly shown in the correlation data, where the left IPL in blind subjects has functional connectivity with right temporal and parietal areas without significant correlation with regions in the left STG. The blind subjects also had positive correlations between the right IPL reference region and right midtemporal and inferior temporal regions, whereas in sighted subjects the inferior temporal areas were negatively correlated with the IPL foci. This suggests that the right midtemporal and inferior temporal gyri in the blind subjects participate in the circuitry for auditory localization in the blind. In sighted subjects, the right hemisphere has for a long time been recognized to have a greater role in the processing of spatial information (Critchley, 1953). Lesions of the right posterior parietal region in humans have a predilection for causing deficits of auditory spatial processing (Heilman and Valenstein, 1972). In blind subjects, exocentric space is dominated by the auditory modality and may, therefore, involve a greater internal construct of external space than in sighted subjects (Thinus-Blanc and Gaunet, 1997).

\section{REFERENCES}

Büchel C, Price C, Frackowiak RS, Friston K (1998) Different activation patterns in the visual cortex of late and congenitally blind subjects. Brain 121:409-419.

Bushara KO, Weeks RA, Ishii K, Catalan M-J, Tian B, Rauschecker JP, Hallett M (1999) Modality-specific frontal and parietal areas for auditory and visual spatial localization in humans. Nat Neurosci 2:759-766.

Cohen LG, Weeks RA, Celnik P, Hallett M (1999) Role of the occipital cortex during Braille reading in subjects with blindness acquired late in life. Ann Neurol 45:451-460.

Colby CL, Goldberg ME (1999) Space and attention in parietal cortex. Annu Rev Neurosci 22:319-349.

Critchley M (1953) The parietal lobes. London: Arnold.

De Volder AG, Catalan-Ahumada M, Robert A, Bol A, Labar D, Coppens A, Michel C, Veraart C (1999) Changes in occipital cortex activity in early blind humans using a sensory substitution device. Brain Res 826:128-134

DeYoe EA, Van Essen DC (1988) Concurrent processing streams in monkey visual cortex. Trends Neurosci 11:219-226.

Friston KJ (1995) Statistical parametric mapping: ontology and current issues. J Cereb Blood Flow Metab 15:361-370.

Grady CL, VanMeter JW, Maisog JM, Pietrini P, Krasuski J, Rauschecker JP (1997) Attention-related modulation of activity in primary and secondary auditory cortex. NeuroReport 8:2511-2516.

Griffiths TD, Brown WD (1991) Focal activation of human left area 19 during an auditory task. J Cereb Blood Flow Metab 11:S374. 
Griffiths TD, Rees G, Rees A, Green GG, Witton C, Rowe D, Buchel C, Turner R, Frackowiak RS (1998) Right parietal cortex is involved in the perception of sound movement in humans. Nat Neurosci 1:74-79.

Grunewald A, Linden JF, Andersen R A (1999) Responses to auditory stimuli in macaque lateral intraparietal area. I. Effects of training. J Neurophysiol 82:330-342.

Haxby JV, Horwitz B, Ungerleider LG, Maisog JM, Pietrini P, Grady CL (1994) The functional organization of human extrastriate cortex: a PET-rCBF study of selective attention to faces and locations. J Neurosci 14:6336-6353.

Hebb DO (1949) The organization of behavior. New York: Wiley.

Heilman KM, Valenstein E (1972) Auditory neglect in man. Arch Neurol 26:32-35.

Horwitz B (1994) Data analysis paradigms for metabolic flow data: combining neural modeling and functional imaging. Hum Brain Mapp 2:112-122.

Horwitz B, McIntosh AR (1993) Network modeling and functional neuroimaging for mapping brain cognitive function. In: Quantification of brain function (Uemera K, Lassen NA, Jones T, Kanno I, eds), pp 589-596. Amsterdam: Excerpta Medica.

Horwitz B, Rumsey JM, Donohue BC (1998) Functional connectivity of the angular gyrus in normal reading and developmental dyslexia. Proc Natl Acad Sci USA 95:8939-8944.

Hubel DH, Wiesel TN (1970) The period of susceptibility to the physiological effects of unilateral eye closure in kittens. J Physiol (Lond) 206:419-436.

Jay JL, Mammo RB, Allan D (1987) Effect of age on visual acuity after cataract extraction. Br J Ophthalmol 71:112-115.

King AJ, Parsons CH (1999) Improved auditory spatial acuity in visually-deprived ferrets. Eur J Neurosci 11:3945-3956.

Kujala T, Alho K, Näätänen R (2000) Cross-modal reorganization of human cortical functions. Trends Neurosci 23:115-120.

Lessard N, Pare M, Leporé F, Lassonde M (1998) Early-blind human subjects sound sources better than sighted subjects. Nature 395:278-280.

Levänen S, Jousmaki V, Hari R (1998) Vibration-induced auditorycortex activation in a congenitally deaf adult. Curr Biol 8:869-872.

Muchnik C, Efrati M, Nemeth E, Malin M, Hildesheimer M (1991) Central auditory skills in blind and sighted subjects. Scand Audiol 20:19-23.

Neville HJ, Bavelier D, Corina D, Rauschecker JP, Karni A, Lalwani A, Braun A, Clark V, Jezzard P, Turner R (1998) Cerebral organization for language in deaf and hearing subjects: biological constraints and effects of experience. Proc Natl Acad Sci USA 95:922-929.

Rauschecker JP (1995) Compensatory plasticity and sensory substitution in the cerebral cortex. Trends Neurosci 18:36-43.

Rauschecker JP (1998) Cortical processing of complex sounds. Curr Opin Neurobiol 8:516-521.
Rauschecker JP, Kniepert U (1994) Enhanced precision of auditory localization behavior in visually deprived cats. Eur J Neurosci 6:149-160

Rauschecker JP, Korte M (1993) Auditory compensation for early blindness in cat cerebral cortex. J Neurosci 13:4538-4548.

Rauschecker JP, Tian B, Hauser M (1995) Processing of complex sounds in the macaque nonprimary auditory cortex. Science 268:111-114.

Röder B, Teder-Sälejärvi W, Sterr A, Rösler F, Hillyard SA, Neville HJ (1999) Improved auditory spatial tuning in blind humans. Nature 400:162-166.

Romanski LM, Tian B, Fritz J, Mishkin M, Goldman-Rakic PS, Rauschecker JP (1999) Dual streams of auditory afferents target multiple domains in the primate prefrontal cortex. Nat Neurosci 2:1131-1136.

Sadato N, Pascual-Leone A, Grafman J, Ibanez I, Deiber M-P, Dold G, Hallett M (1996) Activation of the primary visual cortex by Braille reading in blind subjects. Nature 380:526-528.

von Senden M (1932) Raum-und Gestaltauffassung bei operierten Blindgeborenen vor und nach der Geburt. Leipzig: Barth.

Stricanne B, Andersen RA, Mazzoni P (1996) Eye-centered, headcentered, and intermediate coding of remembered sound locations in area LIP. J Neurophysiol 76:2071-2076.

Talairach J, Tournoux P (1988) Co-planar stereotaxic atlas of the human brain. Stuttgart: Thieme.

Thinus-Blanc C, Gaunet F (1997) Representation of space in blind persons: vision as a spatial sense? Psychol Bull 121:20-42.

Ungerleider LG, Mishkin M (1982) Two cortical visual systems. In: Analysis of visual behaviour. (Ingle DJ, Goodale MA, Mansfield RJW, eds), pp 549-586. Cambridge, MA: MIT.

Watson JD, Myers R, Frackowiak RS, Hajnal JV, Woods RP, Mazziotta JC, Shipp S, Zeki S (1993) Area V5 of the human brain: evidence from a combined study using positron emission tomography and magnetic resonance imaging. Cereb Cortex 3:79-94.

Weeks RA, Aziz-Sultan A, Bushara KO, Tian B, Wessinger CM, Dang N, Rauschecker JP, Hallett M (1999) A PET study of human auditory spatial processing. Neurosci Lett 262:155-158.

Wenzel EM, Arruda M, Kistler DJ, Wightman FL (1993) Localization using nonindividualized head-related transfer functions. J Acoust Soc Am 94:111-123.

Wightman FL, Kistler DJ (1989) Headphone stimulation of free-field listening. I. Stimulus synthesis. J Acoust Soc Am 85:858-867.

Winer BJ (1971) Statistical principles in experimental design. New York: McGraw-Hill.

Woods RP, Cherry SR, Mazziotta JC (1992) Rapid automated algorithm for aligning and reslicing PET images. J Comput Assist Tomogr 16:620-633. 